\title{
English as Foreign Language Students' Understanding and Knowledge of Critical Digital Literacy
}

\author{
Raden Aulia Utami Hidayat*, Didi Suherdi, Pupung Purnawarman \\ English Education Program, Universitas Pendidikan Indonesia \\ *Corresponding author. Email: auliautamihidayat@upi.edu
}

\begin{abstract}
The rapid dissemination of information through the printing press has shifted in the 21 st century as the digital text has become so widespread. In this century, the text comes from various modalities, ranging from traditional texts to technology-based texts. Students are expected to develop a high level of digital use. The challenge of preparing students to be successful, full participants in today's digital society faces all teaches. However, in English as a foreign language country, the current technology instruction system in education mainly concerns on functional technology skills, and critical and reflective components are mostly absent, especially in language education. The present study was conducted to investigate the EFL students' understanding and knowledge of critical digital literacy at the university level in Indonesia. The twenty EFL students from different universities became part of this study. An open-ended online questionnaire was given to them to be analysed inductively in this study in collecting the data. The findings showed that these study participants do not fully know and understand what critical digital literacy is. However, they believe that critical digital literacy will provide them with provisions in the present and future. Therefore, as the recommendation, the socialization related to "critical digital literacy" must be encouraged to have a great generation in this era.
\end{abstract}

Keywords: Critical literacy, critical digital literacy, digital literacy, English as a foreign language

\section{INTRODUCTION}

The development of the era into the 21 st century has brought many changes in various aspects of life. The most obvious change is the development of digital technology that helps people. The digital age has changed how we interact through the media and how we access information (Pérez-Gómez, 2012). It has also influenced all, information, communication and learning areas, whether digital or not (Castellví, Díez-Bedmar, \& Santisteban, 2020). Social and digital media have generated reading and writing practices, which point to a cultural change of prime importance (Pérez-Tornero, 2011), which has not been accompanied by an educational change to help select, discriminate, or evaluating the information in the media.

The changes have challenged the teachers and their eventual students to participate in today's digital society fully. According to Jenkins (2007), the digital society is characterized by a participatory culture that values specific technological and cultural competencies needed to create and communicate through media. The Internet has become one of the primary sources of information and media sharing (Castellví, 2019). However, information on the Internet often reproduces various information and can be inaccurate, or even biased or wrong. These situations encourage teachers and students to understand societal issues and responsibilities in an evolving digital culture and exhibit legal and ethical behaviour in their professional practices.

Furthermore, digital and social media can play a crucial role in fostering democratic participation, social and civic engagement, and social change (Díez-Gutiérrez \& Díaz-Nafría, 2018). However, the current technology instruction system in education focuses primarily on functional technology skills (Polly, Mims, Shepherd, \& Inan, 2010), and critical and reflective components are mostly absent. Therefore, to adapt to the new demands in this era, this study was conducted to investigate the EFL students' understanding and knowledge of critical digital literacy at the university level in Indonesia. This study describes the understanding and knowledge of EFL students of the term "literacy," "critical," and "digital," also the term "critical digital literacy" as a whole. 


\subsection{Critical Digital Literacy}

One of the most important figures of critical pedagogy is Paulo Freire. With critical pedagogy, Freire laid the foundation for what we understand by critical thinking. Freire reconstructs what it means to be a teacher, showing that education should not be a technique or a list of steps to follow but transformative action. Freire and Macedo (2004) also introduced a new meaning for the word "literacy." He understood that through literacy and critical thinking, people could change themselves and change society in the process of liberation. For him, the ability to use the written word is critical to changing the world, and it makes sense that someone learning leads to this praxis. So, according to Freire, literacy will become an attitude, not a mere skill.

In the early 1990s, with ICT still in its infancy, Lankshear and McLaren (1993) published a work that for the first time took critical literacy as its central theme. Influenced by Freire's thesis on reading words to read the world (Freire \& Macedo, 2004), they tried to respond to propositions made in the previous decade regarding critical thinking formation, which they saw as too cognitive. They argue that critical thinking is a skill set and an attitude to information, a way of thinking and living, which must prepare us for action and social transformation.

Critical digital literacy is recent as a field of study, having emerged from critical literacy and critical media literacy, among other fields. It is about developing technology or critical thinking skills and preparing for living in a digital world. Hence, we consider Critical Digital Literacy to be the skills and attitudes needed to search for information, analyse multiple multimodal texts, reflect on information, create narratives and counter-narratives, and act socially on the pursuit of radical democracy and global justice (Castellví, 2019; McDougall, Zezulkova, Van Driel, \& Sternadel, 2018; Santisteban, Díez-Bedmar, \& Castellví, 2020). The activities stated in the previous sentence can be done traditionally and develop into digital-based activities as the times go on.

The term digital literacy has been used to signify a variety of concepts in recent years and remains a contested term. The phrase has disciplinary roots in and relationships with various disciplines, including computer literacy, information and communications technology (ICT) literacy, media literacy, information literacy, and e-literacy. This is reflected in the range of definitions of digital literacy, from mastery of digital technology-related basic skills and competencies' (Bawden, 2008) to digital literacy as 'ideas' (Gilster, 1997). We can further identify two visions of literacy underlying these different approaches. The first extends the traditional definition of literacy to consider new technologies and new formats: the ability to read, write, and otherwise deal with information using the technologies and formats of the time (Bawden, 2008).

The second definition is influenced by a sociocultural perspective; Buckingham (2007) found that what it means to be 'literate' is dynamic and defined in context. Based on this perspective, digital literacy can be seen as a space to do various social practices and conceptions involved in meaning-making through digital technology (Lankshear \& Knobel, 2008). In this definition of digital literacy, functional technology skills are only one piece of a complex digital literacy picture that also includes understanding the social and cultural norms around technology use and the valued practices within those norms. This approach assumes that technology is not neutral; instead, as tools situated within practices, we imbue our technologies with particular values and meanings that may shift depending on context and use. In other words, technologies are both shaped by social and societal forces and synergistically shape how we interact with and make meaning in the world (Pinch \& Bijker, 1984).

This understanding of digital literacy has provided the foundation for the emerging concept of Critical Digital Literacy. Buckingham (2007) suggests that being literate in a given context involves a broader understanding of the social, economic, and institutional contexts of communication and how these affect people's experiences and practices; thus, he views literacy as dynamic situated inherently incorporates a critical perspective. In conclusion, digital literacy is infused by critical pedagogy, critical literacy, and the term Critical Digital Literacy emerges to the surface. Therefore, it could be said that it is essential to examine and critique the text that relates to broader social issues, power relationships, prejudices or inequities, and justice utilized by various digital technology.

\section{METHOD}

To investigate EFL students' understanding and knowledge of critical digital literacy in the Indonesian context, I distributed some questions in the form of an open-ended online questionnaire. This study's participants were twenty EFL students from different universities, from the public to private universities in West Java, Indonesia. The majority of the participants are the freshman, and they are in the second semester of the university. The rest of them are from different grades at the university.

This research has only one research question; this questionnaire's questions were developed based on this study's objectives. The questions on the online form were reviewed by my colleagues (Thomas, 2006) before it was distributed to the participants. The questionnaires were all open-ended and focused on questioning participants' understanding and knowledge of critical digital literacy. 
In the first part, the questions focus on asking the participants' understanding and knowledge of the term's "literacy," "critical," and "digital" individually. Then, the question is expanded, asking where they know these terms and what they think the meaning of these terms. In the last section, all participants are asked about the term "critical digital literacy," whether they know it, and how they understand and know the term. To cover the whole question, their understanding and knowledge of how vital critical digital literacy is to them are also asked.

The inductive content analysis was used to analyse the questionnaire results (Fisher, 2005); data from the questionnaire were analysed to divide it into some emerging themes related to the EFL students' understanding and knowledge of critical digital literacy. It included their understanding and knowledge of the terms as a whole and separately.

\section{FINDINGS AND DISCUSSION}

The following section discusses the findings and discussions from the questionnaire. The findings and discussions are divided into two main issues in accordance with the objective of this research. The first theme examines the participants' understanding and knowledge of the term "literacy," "critical," and "digital," and the second sub-section investigates their understanding and knowledge of "critical digital literacy."

\subsection{The participants' understanding and knowledge of the term "literacy," "critical," and "digital"}

The first theme in the questionnaire was related to EFL students' understanding and knowledge of "literacy," "critical," and "digital" from their perspectives and experience.

Responding to the question asking their understanding and knowledge of the literacy meaning, all of them could answer correctly. They stated that literacy is the ability of reading and writing. Some of them also add the definition of literacy to the ability of reading and writing in order to understand the world.

The extract from participants answers:

"Literacy is the ability to read and write."

"Literacy is a person's ability in reading and writing, increasing knowledge and skills, critical thinking in problem-solving, and the ability to communicate effectively that can develop potential and participate in people's lives."

All the definitions of literacy stated by them are correct. It is in line with the definition of literacy from Kalantzis and Cope (2012); they define literacy as the capability of reading and writing. Furthermore, Freire and Donaldo (1987) explained that literacy presents how the process of meaning-making can change the world in relation to the learning process.

In answering the question of "what does critical mean to you?" the participants mostly define "critical" as the ability to think critically, think logically, and think rationally. Some of them also define critical as the ability to analyse and evaluate the information they get from multiple points of view to know something.

"Being critical, I think, is about how we cope with so much information we got from every reference; we question it first, analyse, compare with other information and then make some summary of it or just understand it without justification."

"Critical, in my opinion, is an attitude that exists in a person to be able to be critical of anything. In that sense, if someone has a critical soul, he will be able to judge and analyse the meaning of the text that he will understand."

"Critical / Critical is usually used with thinking activities, becoming critical thinking. Critical in short means thinking rationally and sensibly and can be accepted by many people."

The definitions of the term "critical" are closely similar to the definition of "critical thinking," based on Luke and Woods (2009), the word "critical" is originated from the Greek word Kritikos, which refers to the capability of judging and arguing. The definitions of critical that participants stated above, such as thinking critically, thinking logically, thinking rationally, and analysing and evaluating the information, are literally relevant to critical thinking. Some critical thinking experts such as Van Sluys, Lewison, and Flint (2006) suggested that students are committed to those skills mentioned before in doing critical thinking.

The last question in this section asked the participants was their understanding and knowledge of the term "digital." The participants' answers to this question are separated into two categories. The first category defines the term digital as every related to technology that helps people's life. The second category defines it scientifically. They stated that digital refers to something that can be read by a machine or whose format is changed so that it can be read or processed by a machine, the other participant stated that digital relates to the approximation of a number for the calculation system, the last participant defined digital as the depiction of the numbers 0 and 1 or off and on, it can also be referred as Bit.

"Digital is everything deals with counting or anything technology-related."

"Something that can be read by a machine or whose format is changed so that it can be read or processed by a machine." 
"Digital relates to the approximation of a number for the calculation system, the last participant defined digital as the depiction of the numbers 0 and 1 or off and on, it can also be referred as Bit (Binary Digit)."

However, this study focused on the definition of digital as showed in the first category. The term digital is defined as the ability to utilized different kinds of technology (Hatlevik \& Christophersen, 2013).

Moreover, they were familiar with the three terms from the Internet. This proves that the level of the use of technological devices has dominated their lives, including in their literacy activities. Pérez-Gómez (2012) explained that the digital age had changed the way we access information and influenced all communication, information, and learning areas.

\subsection{The participants' understanding and knowledge of "critical digital literacy"}

The second theme found in this study is EFL students' understanding of "critical digital literacy" as a whole. The questionnaire showed that one-third of the participants answered that they knew the term "critical digital literacy," one-third of the others answered that they did not know the term, and the rest answered doubtfully about the term. Most of them claim to have read the term via the Internet, but they have never studied critical digital literacy further. Of the twenty participants who took part in this study, two participants chose not to answer questions related to their understanding and knowledge of critical digital literacy. Fortunately, the rest of them tried to answer the question according to their minimal understanding and knowledge of the term. Most of them define critical digital literacy as follows:

"Critical digital literacy is a set of skills, competencies, and analytical viewpoints that allows a person to use, understand, and create digital media and tools."

Some of them also state the meaning of critical digital literacy as:

"The ability to think and learn something in 4.0 industry era, the ability to differentiate what is fact and what is a hoax, the ability to read fast and precise, the ability to summarize information on the digital era, and the ability to think critically on a new information."

The actual meaning of Critical Digital Literacy is the skills and attitudes needed to search for information, analyse multiple multimodal texts, reflect on information, create narratives and counter-narratives, and act socially on the pursuit of radical democracy and global justice (Castellví 2019; McDougall, et al., 2018; Santisteban et al., 2020). Furthermore, Critical Digital Literacy goes more in-depth; it includes understanding the social and cultural norms around technology use and the valued practices within those norms. This approach assumes that technology is not neutral; instead, as tools situated within practices, we imbue our technologies with particular values and meanings that may shift depending on context and use (Pinch \& Bijker, 1984).

Based on all of the participants' answers, in fact, their answers were almost close to the answers expressed by the experts. However, they forget the most essential element in Critical Digital Literacy: its relationship with social practice and issues. The participants only focus on defining the term as the ability to use technology in relation to critical thinking. This seems to illustrate that the participants only combined the definitions of the three terms discussed in the previous session, namely the terms literacy, critical, and digital. However, this is understandable considering that some answered that they were still in doubt and did not even know about the term.

As previously discussed, to cover the whole question, EFL students' understanding and knowledge of how vital critical digital literacy to them is also asked. Overall, the participants answered that understanding and knowledge of Critical Digital Literacy is fundamental, especially for their lives. Below are some extracts from their answers:

"It is important because critical thinking is our provision in the future in receiving and providing information, from and to anyone. In this era of globalization, digital platforms are increasingly in demand, so that many people are competing to digitize everything, including science, information sources, news, and more. Therefore, Critical Digital Literacy is important for us in filtering everything we receive and will also convey."

"I think, yes. As we know, the literacy movement in Indonesia is still lacking. Especially during a pandemic like this, many schools, campuses, and libraries are closed. The only way is to do digital literacy in order to foster a critical attitude as an intellectual student who is literate."

"Yes, it is. Because this term makes students more critical during the pandemic, which requires digital learning both in writing and reading."

Based on the students' extract above, they believe that mastering Critical Digital Literacy skills will help them understand and provide information, especially in their future lives. In addition, they also consider this vital considering that they are now in a pandemic situation that requires them to interact with technology every day.

\section{CONCLUSION}

From the results of the open-ended questionnaire distributed to twenty EFL students at the university, it can be concluded that most of them in this study might not fully understand and know about what Critical Digital Literacy and the essence of it is. This can be seen from 
the results of the analysis of participants' answers in answering questions about their understanding and knowledge of Critical Digital Literacy.

The results showed that there are three significant answers from the participants of this study related to Critical Digital Literacy. First, those who really don't understand and know the term. Second, they are a group that is still in doubt about their answers. Third, those who answered knew and had encountered the term. However, judging from their understanding and knowledge of Critical Digital Literacy, they make great efforts in interpreting it. Unfortunately, most of them only combine the definitions of literacy, critical, and digital and none of them connect Critical Digital Literacy with a social perspective which is the most essential point in this matter. Furthermore, behind their lack of understanding of Critical Digital Literacy, participants responded positively about the importance of understanding these skills for their lives in the digital era and will always develop.

For the recommendation, as the EFL teachers, we have to promote the term Critical Digital Literacy to our students to provide understanding and knowledge related to its importance for them in this $21^{\text {st }}$ century. Therefore, it is not only students who must understand and know this term, but teachers must also have a more fundamental understanding to prepare the desired generation in this era

\section{REFERENCES}

Bawden, D. (2008). Origins and concepts of digital literacy. In C. Lankshear, \& M. Knobel, (Eds.). Digital literacies: Concepts, policies, and practices (pp. 17-32). New York, NY: Peter Lang Publishing.

Buckingham, D. (2007). Digital media literacies: rethinking media education in the age of the Internet." Research in Comparative and International Education 2 (1): 43-55.

Castellví, J. (2019). Critical digital literacy in social studies: case studies in elementary school (Doctoral dissertation). Autonomous University of Barcelona, Bellaterra, Spain.

Castellví, J., Díez-Bedmar, M. C., \& Santisteban, A. (2020). Pre-service teachers' critical digital literacy skills and attitudes to address social problems. Social Sciences, 9(8), 134.

Díez-Gutiérrez, E., \& Díaz-Nafría, J. M. (2018). Ubiquitous learning ecologies for a critical cybercitizenship. Comunicar. Media Education Research Journal, 26(1).

Fisher, A. (2005). Thinking skills and admission to higher education. A special paper, commissioned by the University of Cambridge Local Examinations
Syndicate. and produced by Centre for Research in Critical Thinking, University of East Anglia.

Freire, P., \& Donaldo, M. (1987). Literacy: Reading the word and the world. South Hadley, Mass: Bergin \& Garvey.

Freire, P., \& Macedo, D. (1987). Literacy: reading the word and the world. Hoboken: Taylor \& Francis Ltd.

Gilster, P. (1997). Digital literacy. New York, NY: Wiley.

Hatlevik, O. E., \& Christophersen, K. A. (2013). Digital competence at the beginning of upper secondary school: Identifying factors explaining digital inclusion. Computers \& education, 63, 240-247.

Jenkins, H. (2007). Confronting the challenges of participatory culture: Media education for the 21st century. Nordic Journal of Digital Literacy, 2(1), 23-33.

Kalantzis, M., \& Cope, B. (2012). Literacies. Port Melbourne: Cambridge University Press.

Lankshear, C., \& Knobel, M. (2011). New literacies. McGraw-Hill Education (UK).

Lankshear, C., McLaren, P. L., \& McLaren, P. (Eds.). (1993). Critical literacy: Politics, praxis, and the postmodern. SUNY Press.

Luke, A., \& Woods, A. F. (2009). Critical literacies in schools: A primer. Voices from the Middle, 17(2), 918.

McDougall, J., Zezulkova, M., Van Driel, B., \& Sternadel, D. (2018). Teaching media literacy in Europe: Evidence of effective school practices in primary and secondary education, NESET II report.

Pérez-Gómez, A. I. (2012). Educarse en la era digital. Madrid: Morata.

Pérez Tornero, J. M. (2011). El aprendizaje de la lectura comprensiva y crítica. Leer. es.

Pinch, T. J., \& Bijker, W. E. (1984). The social construction of facts and artefacts: Or how the sociology of science and the sociology of technology might benefit each other. Social studies of science, 14(3), 399-441.

Polly, D., Mims, C., Shepherd, C. E., \& Inan, F. (2010). Evidence of impact: Transforming teacher education with preparing tomorrow's teachers to teach with technology (PT3) grants. Teaching and Teacher Education, 26(4), 863-870.

Santisteban, A., Díez-Bedmar, M. C., \& Castellví, J. (2020). Critical digital literacy of future teachers in the Twitter age. Culture \& Education, 32(2), 1-28. 
Thomas, D. R. (2006). A general inductive approach for analyzing qualitative evaluation data. American journal of evaluation, 27 (2), 237-246.

Van Sluys, K., Lewison, M., \& Flint, A. S. (2006).

Researching critical literacy: A critical study of analysis of classroom discourse. Journal of Literacy Research, 38(2), 197-233. 